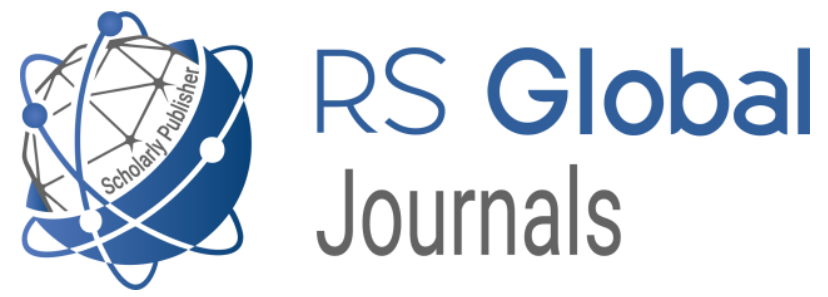

Scholarly Publisher RS Global Sp. z O.O. ISNI: 0000000484952390

Dolna 17, Warsaw, Poland 00-773

Tel: +48226022703

Email: editorial_office@rsglobal.pl

\begin{tabular}{ll} 
JOURNAL & Science Review \\
\hline p-ISSN & $2544-9346$ \\
\hline e-ISSN & $2544-9443$ \\
\hline PUBLISHER & RS Global Sp. z O.O., Poland
\end{tabular}

ARTICLE TITLE

PHARMACOLOGICAL VIEW ON THE PROBLEM OF COMORBIDITY IN THE PHARMACOTHERAPY OF CHRONIC PANCREATITIS

$\operatorname{AUTHOR}(\mathbf{S})$

Iryna Tukhar, Viktoriya Shapovalova, Valentyn Shapovalov, Valeriy Shapovalov

Iryna Tukhar, Viktoriya Shapovalova, Valentyn Shapovalov, Valeriy Shapovalov. (2021) Pharmacological View on the

ARTICLE INFO Problem of Comorbidity in the Pharmacotherapy of Chronic Pancreatitis. Science Review. 3(38). doi:

10.31435/rsglobal_sr/30072021/7591

DOI

https://doi.org/10.31435/rsglobal_sr/30072021/7591

RECEIVED

08 April 2021

ACCEPTED

25 May 2021

PUBLISHED

31 May 2021

LICENSE

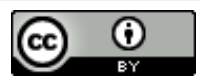

This work is licensed under a Creative Commons Attribution

4.0 International License.

(C) The author(s) 2021. This publication is an open access article. 


\title{
PHARMACOLOGICAL VIEW ON THE PROBLEM OF COMORBIDITY IN THE PHARMACOTHERAPY OF CHRONIC PANCREATITIS
}

\author{
Iryna Tukhar, Lviv Medical Professional College "Monada", Lviv Regional Clinical Hospital, \\ Ukraine, ORCID ID: https://orcid.org/0000-0002-6827-402X \\ Viktoriya Shapovalova, Kharkiv Medical Academy of Postgraduate Education, Doctor of Pharmacy, \\ Professor, Ukraine, ORCID ID: https://orcid.org/0000-0003-4770-7292 \\ Valentyn Shapovalov, Kharkiv Medical academy of Postgraduate Education, Doctor of Pharmacy, \\ Professor; Advocates Company "Apotheosis", corresponding author, Ukraine, \\ ORCID ID: https://orcid.org/0000-0002-9329-0195 \\ Valeriy Shapovalov, Lviv Medical Institute LLC, Doctor of Pharmacy, Professor, Ukraine, \\ ORCID ID: https://orcid.org/0000-0002-6696-6380.
}

DOI: https://doi.org/10.31435/rsglobal_sr/30072021/7591

\section{ARTICLE INFO}

Received 08 April 2021

Accepted 25 May 2021

Published 31 May 2021

\section{KEYWORDS}

clinical pharmacy, chronical pancreatitis, comorbidity, drugs, pharmacotherapy.

\begin{abstract}
The article presents the results of the research concerning the pharmacotherapy of patients with chronic pancreatitis with comorbidity from the pharmacological view. During the study pharmacological approach to the problem of comorbidity among patients with chronic pancreatitis was analyzed. A survey among doctors and pharmacists was used during the research along with normative and legal, documentary, retrospective, bibliographic, systemic, forensic-pharmaceutical, sociological (questionnaire survey), comparative, graphic, mathematical analysis methods. The most common comorbid diseases that patients suffer from alongside with chronic pancreatitis were highlighted. Authors came to conclusion, that development of safe and affordable pharmaceutical therapy for patients with chronic pancreatitis and comorbidity is very important.
\end{abstract}

Citation: Iryna Tukhar, Viktoriya Shapovalova, Valentyn Shapovalov, Valeriy Shapovalov. (2021) Pharmacological View on the Problem of Comorbidity in the Pharmacotherapy of Chronic Pancreatitis. Science Review.3(38). doi: 10.31435/rsglobal_sr/30072021/7591

Copyright: (C) 2021 Iryna Tukhar, Viktoriya Shapovalova, Valentyn Shapovalov, Valeriy Shapovalov. This is an open-access article distributed under the terms of the Creative Commons Attribution License (CC BY). The use, distribution or reproduction in other forums is permitted, provided the original author(s) or licensor are credited and that the original publication in this journal is cited, in accordance with accepted academic practice. No use, distribution or reproduction is permitted which does not comply with these terms.

Introduction. In recent years, the topic of comorbidity or "double disorders" is devoted to numerous studies in Western literature - pharmacological, epidemiological, clinical, forensic, pharmaceutical, pharmacoeconomic, legal $[1,2,3]$.

The term "comorbidity" or "dual diagnosis" recognizes the presence of two or more health disorders of same patient at the same time $[4,5]$.

In the English-language literature, special attention is paid to the problem of "double disorders" or "double diagnoses". However, in the Ukrainian-language literature this problem has not yet received sufficient coverage [6].

Special importance given to the comorbidity in the ICD-10, as the emphasis is on unified and standardized criteria for health disorders, which allows diagnosing several health disorders simultaneously [7].

Only $12 \%$ of clinical guidelines used in Australia and $44 \%$ of clinical guidelines in the United States provide specific guidelines for patients with comorbid conditions [8]. 
From a pharmacological point of view, the problem of comorbidity is relevant in the pharmacotherapy of health disorders, when it is necessary to properly prescribe drugs. Comorbidity in the pharmacotherapy of chronic pancreatitis (CP) is no exception in this sense. The name $\mathrm{CP}$ is understood as a chronic inflammatory disease of the pancreas, accompanied by irreversible structural changes (fibrous, cystic - to limbs atrophic), the development of excretory and incretory insufficiency manifested by abdominal pain and characterized by a significant decrease in quality of life. Current world data show an increase in the number of patients with CP. The incidence of CP in European countries ranges from 5 to 10 per 100,000 population. In general, the world has a tendency to increase the incidence of CP over the past 30 years by more than 2 times [9].

The purpose of the research was to analyze the pharmacological approach to the problem of comorbidity among patients with $\mathrm{CP}$.

Materials and methods. The current research was carried out using the system approach during April 2020 - April 2021. A survey of doctors and pharmacists (57), who underwent thematic improvement at the Department of Medical and Pharmaceutical Rights, General and Clinical Pharmacy of the Kharkiv Medical Academy of Postgraduate Education. The questionnaire included questions that allowed describing the respondents: age, gender, position, qualification category, work experience. The questionnaire also included questions for clinical and pharmaceutical analysis in the following areas: 1) frequency of contact with a doctor per year of patients with CP in the absence of comorbid diseases; 2) the frequency of contact with the doctor for a year of patients with $\mathrm{CP}$ in the presence of one comorbid disease; 3 ) frequency of contacts with the doctor for a year of patients with $\mathrm{CP}$ in the presence of 2 comorbid diseases; 4) frequency of contacts with the doctor for a year of patients with $\mathrm{CP}$ in the presence of more than 3 comorbid diseases; 5) comorbid conditions that accompanied patients with CP.

The information base of the study consisted of scientific works of foreign and domestic scientists on issues related to the clinical pharmacy, organization of pharmaceutical business, management, forensic pharmacy, pharmaceutical supply, pricing policy for drugs [10-13].

Modern research methods were used: normative and legal, documentary, retrospective, bibliographic, systemic, forensic-pharmaceutical, sociological (questionnaire survey), comparative, graphic, mathematical analysis. Mathematical processing and statistical evaluation of data was performed using Microsoft Excel.

The study of the article is a fragment of research work of the Kharkiv Medical Academy of Postgraduate Education on "Improving the organizational and legal procedure for providing patients with drugs from the standpoint of forensic pharmacy, organization and management of pharmacy" (state registration number 0116U003137, deadline 2016-2020) and "Pharmaceutical and medical law: integrated approaches to the drug circulation system from the standpoint of forensic pharmacy and organization of pharmaceutical business" (state registration number D/21U000031, deadline 2021-2026) [14-16].

Research results. Based on a review of the scientific literature, there are several classifications of types of comorbidity. According to the time of onset of the main disorder (CP), comorbidity is divided into primary, secondary and independent. Due to the complexity of establishing the primacy, the following types of pharmacological relationship between primary $(\mathrm{CP})$ and comorbid health disorders can be identified: 1 - comorbid disorders increase the risk of complications of CP; 2 - the course of CP is exacerbated by mental, narcological, cardiac, surgical, oncological, immune, addictive and other diseases; 3 - symptoms of CP may be under the indirect (psychosocial) influence of comorbid disorders; 4 -over time, due to the strength of the relationship, it is impossible to establish the primacy of the main and comorbid disorders; double disorders can develop at different intervals [17].

It is important to assess the severity of underlying $(\mathrm{CP})$ and comorbid disorders. There are four possible combinations: both problems are easy (1); severe underlying disorder (CP) and mild comorbid disorder (2); mild underlying disorder (CP) and severe comorbid disorder (3); severe underlying disorder and severe comorbid disorder (4).

For example, in Brazil, over $88 \%$ of people over the age of 40 have at least one major chronic disease, and $26 \%$ have more than two major comorbid conditions [18].

The next task of the study included the analysis of a sociological survey by questionnaires of respondents. The characteristics of the respondents of the Department of Medical and Pharmaceutical Law, Forensic and Clinical Pharmacy are given in Table 1. 
Table 1. Characteristics of respondents

\begin{tabular}{|c|c|c|}
\hline No. & Question & Result \\
\hline 1. & Age & Average age is $49,5 \pm 2,5$ years \\
\hline 2. & Sex & Female $24 \%$ \\
Male $76 \%$
\end{tabular}

According to the results of a survey of respondents of the Department of Medical and Pharmaceutical Rights, General and Clinical Pharmacy of the Kharkiv Medical Academy of Postgraduate Education, it was found that patients with $\mathrm{CP}$ had an average of two visits per year in the absence of comorbid diseases; and in the presence of one, two and more than three comorbid diseases, their number increased to seven, eleven and fourteen, respectively.

The results of the questionnaire showed that $\mathrm{CP}$ was accompanied by comorbid gastroenterological, surgical, therapeutic, cardiac, addictive, neurological, psychiatric, oncological conditions in 5-65\% of cases. The share of comorbid pathology of gastroenterological practice was $33 \%$ of cases (chronic gastritis - in 17\% of cases; duodenal ulcer - in 15\%; chronic cholecystitis - in 19\%); surgical practice - from $10 \%$ to $25 \%$ of cases; therapeutic practice - up to $12 \%$ of cases; cardiac practice from $6 \%$ to $35 \%$ of cases; addictive practice - up to $65 \%$ of cases; neurological practice - up to $24 \%$ of cases; psychiatric practice - from 5\% to $11 \%$ of cases; oncological practice - up to $29 \%$ of cases.

On the other hand, for patients with addictive health disorders, the most common among comorbid diseases were diseases of the digestive system: intestinal diseases (colon irritation syndrome, chronic colitis) in 59\%; diseases of the liver, gallbladder and biliary tract (chronic hepatitis, non-alcoholic fatty hepatosis) $-43 \%$; diseases of the pancreas (chronic pancreatitis) - 28\%; diseases of the stomach and duodenum (gastroesophageal reflux disease, gastric and duodenal ulcers, chronic gastritis) $-40 \%$. The number of prescribed drugs increased from five to seven, and from ten and fourteen respectively.

The importance of the problem of comorbidity for practical activities is primarily due to the fact that the presence of several chronic diseases leads to deterioration in quality of life. Thus, a questionnaire survey using the SF-36 questionnaire, conducted among respondents to the Department of Medical and Pharmaceutical Rights, General and Clinical Pharmacy of the Kharkiv Medical Academy of Postgraduate Education, showed a significant decrease in quality of life, especially in everyday activities. Comorbidity leads to increased costs for diagnostic examinations and treatment, increases the length of hospitalization, is the most common cause of non-specialized hospitalization of patients and reduces the operational activity of health care facilities.

Discussion. In clinical pharmacy, comorbid disorders or comorbidities are a problem when prescribing drugs to patients suffering from both $\mathrm{CP}$ and bipolar disorder. The most common comorbid diseases among patients with $\mathrm{CP}$ - abusing of psychoactive substances: drugs and alcohol. Alcohol abuse (up to 60\%) or drugs (up to 50\%) are often accompanied by bipolar disorder on the background of CP. This means that 50 to 60 percent of patients with $\mathrm{CP}$ suffer from comorbid addictive addiction to psychoactive substances at least once in their lifetime. On the other hand, addictive dependence on surfactants has a bad effect on the course of the underlying disease, resulting in an increase in the frequency of attacks, more cases of hospitalization. The problem of polymorbidity of therapeutic patients is also growing, which is due to the tendency to general aging of the population, "rejuvenation" and an increase in the number of cases of chronic diseases, increasing the impact of negative environmental factors [19]. 
According to studies conducted in the Netherlands, among people aged $45-64,7 \%$ have more than four comorbid diseases; in the age group 65-74 years the frequency increases to 30\%; among persons older than 75 years the frequency is 55\%. A 2005 study in Quebec province found that among patients aged 45 to 64 , more than $95 \%$ of women and more than $89 \%$ of men had more than two comorbid diseases. The prevalence of comorbid conditions ranges from $69 \%$ among young patients to $93 \%$ among middle-aged patients and up to $98 \%$ among elderly patients. The number of multimorbid conditions increases from $10 \%$ among patients over 19 years of age to $80 \%$ among patients over 80 years of age [20].

For comparison: information from the Australian National Registry shows that more than $50 \%$ of cancer patients had comorbid arthritis; $15.1 \%$ - bronchial asthma; $16.1 \%$ - concomitant mental illness; $14.6 \%$ - cardiovascular pathology. Among the participants in the registry, $32.3 \%$ of patients had one major disease; among 9.6\% - two (basic and comorbid); among 2.5\% - three (basic and two comorbid) [8].

In the Netherlands, $79 \%$ of older patients have more than two diseases. Among patients with the national cancer registry of the Netherlands, comorbidities range from $12 \%$ (age group over 45 years) to $60 \%$ (over 70 years). In the United States and Australia, 55 to $80 \%$ of patients over the age of 65 have more than two chronic diseases [21].

Comorbid, polymorbid diseases can significantly affect the diagnosis and pharmacotherapy of patients with CP. Blind use of the provisions of the recommendations and clinical guidelines without taking into account the clinical condition of a particular patient, in particular the presence of comorbid pathology, can lead to deterioration of treatment results and the development of complications [22, 23].

According to foreign scientists, the provision of medical and pharmaceutical care to patients with comorbid diseases requires an increase in health care costs. Thus, in the United States, more than $80 \%$ of medical insurance (Medicare program) goes to cover the cost of medical care for patients with more than four diseases with a chronic course [24 - 26].

Conclusions. The search for pharmacological ways to solve the problem of comorbidity among patients with chronic pancreatitis $(\mathrm{CP})$ is a topical issue. Therefore, the development of safe pharmacotherapy regimens for chronic pancreatitis (CP) and comorbid health disorders is important for pharmacology and remains little studied for clinical pharmacy. Thus, future researches needed in the field of the study.

Declaration of Interest Statement. The authors declare that they have no known competing financial interests or personal relationships that could have appeared to influence the work reported in this paper.

\section{REFERENCES}

1. Boyd C.M., Darer J., Boult C. et al. (2005) Clinical practice guidelines and quality of care for older patients with multiple comorbid diseases: implications for pay for performance. JAMA, 294(6): 716-724.

2. Dawes M. (2010) Co-morbidity: we need a guideline for each patient not a guideline for each disease. Fam. Pract., 27(1): 1-2.

3. Fortin M., Bravo G., Hudon C. et al. (2005) Prevalence of multimorbidity among adults seen in family practice. Ann. Fam. Med., 3(3): 223-228.

4. Comorbidity. Retrieved from http://www.plaintest.com/psychiatry/comorbidnost.

5. Belousov Yu. V. (2012) Comorbidity in diseases of the digestive system. Zdorovya rebenka, 1 (36): 134-136.

6. Campbell-Scherer D. (2010) Multimorbidity: a challenge for evidence-based medicine. Evid. Based Med., 15(6): 165-166.

7. Ministry of healthcare of Ukraine official site. Retrieved from http://moz.gov.ua/ (application date 07.05.2018). Title from the screen.

8. Caughey G.E., Vitry A.I., Gilbert A.L., Roughead E.E. (2008) Prevalence of comorbidity of chronic diseases in Australia. BMC Public Health, 8: 221.

9. Löhr J. M. United European Gastroenterology evidence-based guidelines for the diagnosis and therapy of chronic pancreatitis // United European Gastroenterology Journal. 2017. Vol. 5, Issue 2. P. 153-199. doi: http://doi.org/ 10.1177/2050640616684695

10. Experience of Great Britain in organization of healthcare system for pharmaceutical provision with medicines for privileged categories of citizens / V.V. Shapovalov (Jr.), V.O. Shapovalova, V.V. Andrieieva, V.V. Shapovalov. Health of society. 2019. Vol. 78, N. 1. P. 36-40. (doi: 10.22141/2306-2436.8. 1.2019.172617).

11. Experience of Poland concerning and organization of healthcare system for the pharmaceutical provision for privileged categories of citizens / V.V. Shapovalov (Jr.), A.O. Gudzenko, V.A. Shapovalova, V.V. Andrieieva, V.V. Shapovalov. Proceeding of articles the international scientific conference "Advance of Science». Czech Republic, Karlovy Vary - Ukraine, Kyiv, 17 May 2019. Czech Republic, Karlovy Vary: Skleněný Můstek - Ukraine, Kyiv: MCNIP, 2019. P. 16-22. 
12. Experience of the USA concerning and organization of healthcare system for the pharmaceutical provision for privileged categories of citizens / V.V. Shapovalov (Jr.), A.A. Gudzenko, V.V. Andrieieva, V.A. Shapovalova, V.V. Shapovalov Annals of Mechnikov Institute. 2019. N. 1. P. 81-87. (doi: 10.5281/zenodo.2639521).

13. Freeman J. S. Providing whole-person care: integrating behavioral health into primary care. N.C. Med.J. 2015. Vol. 76, N 1. P. 24-25, 27-28.

14. Concerning the importance of forensic and pharmaceutical researches to improve patients' accessibility to medicines / V. Shapovalov, A. Gudzenko, L. Komar, A. Butko, V. Shapovalova, V.Shapovalov. Pharmacia. 2017. Vol. 65. N. 2. P. 23-29.

15. Forensic and pharmaceutical study of the presence of a causal link between the degree of alcohol abuse and qualification level of the respondents / V. Shapovalov, A. Gudzenko, V. Shapovalova, A. Osyntseva, V. Shapovalov. Pharmacia. 2017. Vol. 66, N. 3. P. 31-39.

16. Organizational and legal evaluation of availability of medicines' circulation for cancer patients / V.V. Shapovalov, S.I. Zbrozhek, V.O. Shapovalova, V.V. Shapovalov. Pharmacia. 2018. Vol. 65, N. 2. P. 17-22.

17. Chernobrovkina T.V., Artemchuk A.F. The problem of comorbidity and modern forms of alcoholic disease (clinical and pathogenetic aspect). Narcology, 12/2006, 47-74 pp.

18. Carvalho A.K., Menezes A.M., Camelier A. et al. (2012) Prevalence of self-reported chronic diseases in individuals over the age of 40 in São Paulo, Brazil: the PLATINO study. Cad. Saude Publica, 28(5): 905-912.

19. Caughey G.E., Roughead E.E. (2011) Multimorbidity research challenges: where to go from here? Journal of Comorbidity, 1: 8-10.

20. Coebergh J.W., Janssen-Heijnen M.L., Post P.N., Razenberg P.P. (1999) Serious co-morbidity among unselected cancer patients newly diagnosed in the southeastern part of The Netherlands in 1993-1996. J. Clin. Epidemiol., 52(12): 1131-1136.

21. Caughey G.E., Ramsay E.N., Vitry A.I. et al. (2010) Comorbid chronic diseases, discordant impact on mortality in older people: a 14-year longitudinal population study. J. Epidemiol. Community Health, 64(12): 1036-1042.

22. Health insurance and mortality in US adults / A. P. Wilper, S. Woolhandler, K. E. Lasser, D. McCormick, D. H. Bor. American Journal of Public Health. 2009. Vol. 99. N. 12. P. 2289-2295.

23. WHO Drug Information. Retrieved from http://www.who.int/medicines/publications/druginformation/en. (application date 07.05.2018). Title from the screen.

24. Ford, C. D., Killebrew, J., Fugitt, P., Jacobsen, J., \& Prystas, E. M. (2006). Study of medication errors on a community hospital oncology ward. Journal of oncology practice, 2(4), 149-154. Retrieved from http://www.ncbi.nlm.nih.gov/pmc/articles/PMC2793607/. (application date 07.05.2018).

25. Heilmann P. To have and to hold: personnel shortage in a Finnish healthcare organisation. Scand. J. Public. Health. 2010. Vol. 38. N. 5. P. 518-523.

26. Meta D., Shukhov V., Chuchalin A. The British national form (politics, structure, features, example for imitation). Retrieved from http://evbmed.fbm.msu.ru/rwinwww/publica/bnf.html (application date 24.07.2017). Title from the screen. 